\title{
Comunicação
}

[Communication]

\section{Registro de ácaros em avestruz no estado do Rio de Janeiro}

\author{
[Report of mites in ostrich in Rio de Janeiro State] \\ D.G. Mattos $J r^{1}$, J.A. Amaral ${ }^{2}$, M. Porto ${ }^{2}$, L.P.L. Fedullo ${ }^{2}$, \\ L.M.C. Balthazar ${ }^{2}$, P. Tucunduva ${ }^{3}$ \\ ${ }^{1}$ Universidade Federal Fluminense \\ Rua Dr. Vital Brazil Filho, 64 \\ 24230-050 - Niterói, RJ \\ ${ }^{2}$ Fundação Educacional Serra dos Órgãos - Teresópolis, RJ \\ ${ }^{3}$ Médica veterinária autônoma
}

Entre as doenças que ocorrem em avestruzes, os ecto e endoparasitos contribuem de forma significativa por determinar perdas econômicas não só associadas à mortalidade de indivíduos como também à queda do rendimento de carcaça, ao atraso na idade do abate e à baixa eclodibilidade dos ovos (Tully e Shane, 1996).

Os ectoparasitos de avestruzes registrados por investigadores são os piolhos, acarinos e larvas de carrapatos, que podem agir como causadores de queda de penas e irritação do animal (Craig, 1993; Huchzermeyer, 1999; Ponce-Gordo et al., 2002; Proctor, 2003). Essas ocorrências de infestações foram registradas em diversos países, tais como a Austrália, Estados Unidos e Espanha (Ponce-Gordo et al., 2002).

Devido ao crescimento da estrutiocultura no Brasil e sua importância econômica, o objetivo do presente trabalho é registrar a ocorrência de infestação por ácaros em avestruz.

Em uma criação de avestruzes com 50 cabeças, provenientes da região da Baixada Fluminense, estado do Rio de Janeiro, um exemplar macho, de três anos de idade, apresentou áreas desplumadas na região das asas, com queda de penas e irritação na pele. A ave foi separada do plantel e tratada com injeção de ivermectina $200 \mathrm{mcg} / \mathrm{kg}$, no músculo do peito em dose única.
As penas foram colhidas diretamente da asa esquerda da ave, acondicionadas em isopor e enviadas para análise no laboratório.

Procedeu-se ao preparo do material de acordo com as técnicas usuais em parasitologia, sendo estes artrópodes montados em preparações permanentes, entre lâmina e lamínulas, com bálsamo do Canadá, sendo posteriormente identificados de acordo com Dubinin (1956) e Gaud e Atyeo (1996).

Os ácaros foram fotomicrografados com o auxílio de câmara digital Sony Cybershot P93, diretamente da ocular do microscópio óptico.(Fig.1 e 2).

Nas penas examinadas com o auxílio do estereomicroscópio, observaram-se massas de ovos fixadas às bárbulas da base das penas, assim como no interior dos cálamos, que apresentavam-se quebradiços e ressecados (Fig. 3). Um grande número de espécimens de ácaros, em diferentes estágios ninfais e adultos, foram observados e identificados como representantes da espécie Struthiopterolichus sculpturatus (Hirst), pertencentes à família Pterolichidae (Acari : Pterolichoidea), de acordo com as descrições de Dubinin (1956) e Gaud e Atyeo (1996). 


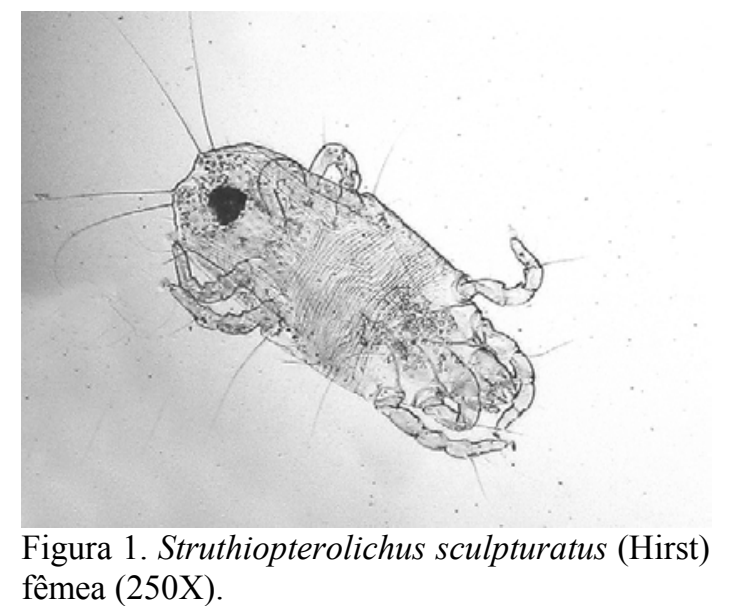
fêmea (250X).

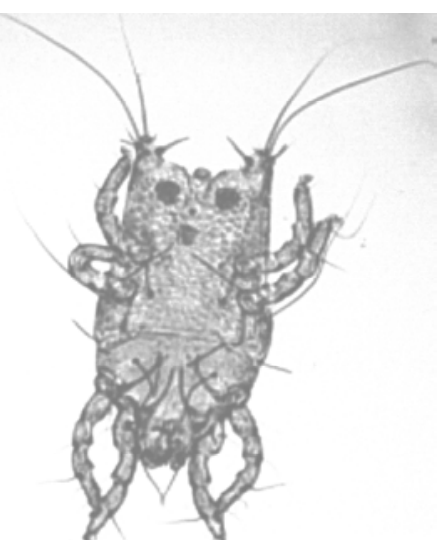

Figura 2. Struthiopterorichus sculpturatus (Hirst), macho (250X).

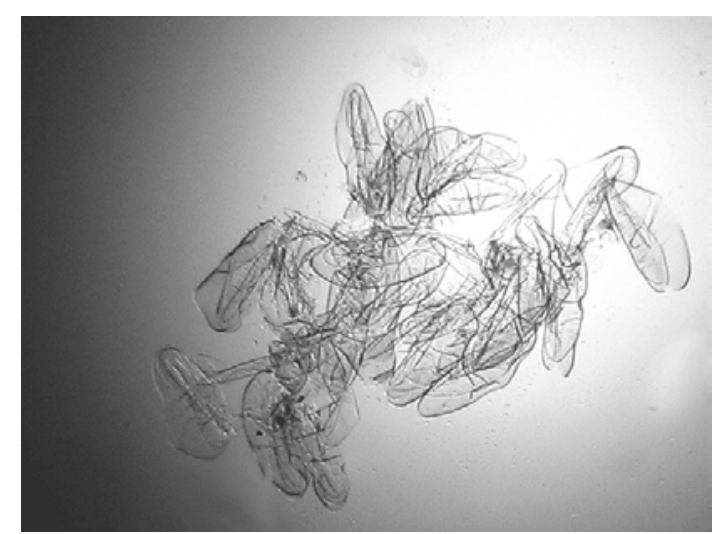

Figura 3. Ovos de ácaros recuperados dos cálamos das penas de avestruzes (250X).

Segundo Proctor (2003), existem aproximadamente 2.000 espécies listadas de ácaros das plumas de aves. Quase todos são simbiontes obrigatórios, vivendo no interior ou sobre a pele (dermícolas), no interior do cálamo (siringícolas) e sobre as penas (plumícolas). No entanto, a autora registra a existência de divergências quanto ao rearranjo de determinadas famílias e gêneros, dificultando a identificação das espécies. Ainda, Proctor (2003) aceita a classificação de Gaud e Atyeo (1996) com relação às três superfamílias de acarinos das penas de aves e seus respectivos hospedeiros. Estes investigadores listam representantes das famílias Dermoglyphidae (Analgoidea) e Pterolichidae (Pterolichoidea) como ácaros que estão associados aos estrutioniformes.

Segundo O'Connor (1982), os Dermoglyphidae consomem fluídos das papilas na base das penas e os Pteroclichidae, alguns siringícolas, se alimentam também sobre as penas, mas podem penetrar no cálamo, enfraquecendo as mesmas, proporcionando sua quebra e queda prematura.

Ponce-Gordo et al. (2002), ao estudarem diversas criações comerciais de avestruzes e emas na Espanha, registraram a ocorrência de Dermoglyphus pachycnemys, que, apesar de não pertencer à família Pterolichidae são muito semelhantes aos espécimens de $S$. sculpturatus identificados neste trabalho.

Os aspectos morfológicos descritos são semelhantes aos apresentados por Proctor (2003), sendo os ácaros portadores das seguintes características: corpo achatado dorsoventralmente, patas curtas inseridas lateralmente ao corpo, ambulacros tarsais grandes para auxiliar na sua fixação às bárbulas das penas e $\mathrm{o}$ corpo, em sua face dorsal, apresenta-se tipicamente bem esclerotizado, características validadas para espécimens de ácaros $S$. sculpturatus.

Quanto à importância desses ácaros como agentes causadores de patologias em avestruzes, reserva-se o cuidado de não afirmá-las, pois ainda existem dúvidas se devem ser parasitos ou simbiontes (Proctor, 2003). Diante das observações concernentes aos sinais clínicos e recuperação após tratamento, sugere-se que a infestação por S. sculpturatus pode estar associada à queda de penas em avestruzes.

Palavras-chave: avestruz, ácaros, penas 


\begin{abstract}
For the first time, it was identified a mite in a three-year-old male ostrich that had lost feathers and showed skin irritation. The animal belonged to a flock of 50 birds, located in Baixada Fluminense, in Rio de Janeiro State. After they were fixed in $70 \%$ alcohol, clarifyed in lactophenol and mounted in Canada balsam, the mites were identified in the laboratory. They belonged to the Pterolichidae family and Struthioperolichus sculpturatus species (Hirst). The ostrich was treated by ivermectin in dose of $200 \mu \mathrm{g} / \mathrm{kg}$ of body weight, with recovery and disappearance of the clinical symptoms. The occurrence of mite infestation by the described species in ostrich should be monitored by professionals and farmers, as they cause fall of feathers and economic losses.
\end{abstract}

Keywords: ostrich, mites, feathers

\section{AGRADECIMENTOS}

Aos acadêmicos Felipe Bath do curso de Veterinária - UFFRJ e Paulo Deslandes, monitor da disciplina de Doenças Parasitárias da Fundação Educacional Serra dos Órgãos. Ao Prof. Elmiro Rosendo do Nascimento da Faculdade de Veterinária - UFF pela revisão do abstract. À Dra. Heather Proctor da Universidade de Alberta - Canadá, pelo envio da bibliografia e artigos originais.

\section{REFERÊNCIAS BIBLIOGRÁFICAS}

CRAIG, T. Natural parasites of ratites. In: ANNUAL RATITE CONFERENCE. 1993. College Station, Texas: College of Veterinary Medicine, Texas A \& M University,1993.

DUBININ, W.B. Perevyie Idesci (Analgesoidea). III. Semejstwo Pterolichidae. Fauna SSR, v.66, p.131, 1956.
GAUD, J.; ATYEO, W.T. Feather mites of the world (Acarina:Astigmata) the supraespecific taxa. Part I. Ann. Zool. Wet., v.277, p.1-193, 1996.

HUCHZERMEYER, F.W. Patologia de avestruces y otras ratites. Madrid: Ediciones Mundi-Prensa, 1999. 284p.

O'CONNOR, B.M. Evolutionary ecology of astigmatid mites. Annu. Rev. Entomol., v.27, p.385-409, 1982.

PONCE-GORDO, F.; HERRERA, S.; CASTRO, A. T. et al. Parasites from farmed ostriches (Struthio camelus) and rheas (Rhea americana) in Europe. Vet. Parasitol., v.107, p.137-60, 2002.

PROCTOR, H. Feather mites (Acari:Astigmata): ecology, behavior and evolution. Annu. Rev. Entomol., v.48, p.185-209, 2003.

TULLY, T.N.; SHANE, S.M. Husbandry practices as related to infections and parasitic diseases of farmed ratites. Vet. Sci. Tech. Off. Int. Epiz., v.15, p.73-79, 1996. 